\title{
GUIDING SCHOOLS TO IMPROVED PERFORMANCE USING DATA ENVELOPMENT ANALYSIS: AN ILLUSTRATION WITH DATA FROM A LOCAL EDUCATION AUTHORITY\$
}

\author{
by \\ E THANASSOULIS \& P DUNSTAN\$ \\ Warwick Business School, \\ University of Warwick, Coventry CV4 7AL
}

\begin{abstract}
The educational process is characterised by multiple outcomes such as the achievement of academic results of various standards and non-academic achievements. This paper shows how data envelopment analysis (DEA) can be used to guide secondary schools to improved performance through role-model identification and target setting in a way which recognises the multi-outcome nature of the education process and reflects the relative desirability of improving individual outcomes. The approach presented in the paper draws from a DEA-based assessment of the schools of a local education authority carried out by the authors. Data from that assessment are used to illustrate the approach presented in the paper. (Key words: Data envelopment analysis, education, target setting.)
\end{abstract}

\$ An earlier version of this paper was presented at the annual conference of the Operational Research Society, OR34, September 1992, Birmingham.

\$ Now at United Parcel Service Ltd, 391 Richmond Road, Twickenham, London. 



\section{INTRODUCTION}

This paper shows how data envelopment analysis (DEA) can be used to guide schools to improved performance through target setting and role-model identification. It is argued that targets a school is set and the role-models it is to emulate in order to improve its performance need to reflect the relative desirability of improving individual outcomes of the education process at the school. While the method developed can be adapted for schools catering for pupils of any age, its development is with reference to UK schools teaching pupils between the ages of 11 and 15 . The paper assumes the reader is broadly familiar with DEA and it gives technical details only of the specific DEA models and concepts used in the approach developed in this paper. The interested reader can find introductory reviews of DEA in Dyson et al1 and in Boussofiane et al2.

There exists a broad consensus that the outcomes of the education process are multiple. Academic achievements, such as those reflected in the grades pupils obtain in public examinations, are an important outcome of the education process. However, it is generally accepted that academic achievements are only one of a range of desirable educational outcomes. Schools also foster progress in non-academic areas such as music, sport and social skills.

The measurement of the effectiveness of schools has been the focus of much attention within the community in general. This is particularly so in the UK where the government's recent "Parents' Charter" has led to the statutory publication of league tables of schools on examination results.

League tables based on academic results have been heavily criticised mainly for the fact that they do not take account of factors beyond the control of schools. One important such factor is the entrance standards of pupils. Rather than indicating the educational value added by each school, league tables it is argued largely reflect the initial abilities of the pupils on transfer to the school. Schools with 
intakes of above average ability pupils are unfairly advantaged by such league tables. League tables also take no account of parental background or level of "socio-economic advantage". A number of studies (eg Hutchinson et al3, Gray4 and Jesson and Gray5) have linked social factors such as parental income or social class to subsequent performance.

In search of a fairer way to compare the performance of schools thinking converges on the use of methods which make it possible "to contextualise" examination results by making allowances for factors such as academic ability of pupils on entry to school and their socio-economic background. For example Gray et al6 suggest the use of approaches such as regression analysis and "variance components" while Mayston and Jesson7 contrast regression analysis and DEA as alternative methods that make it possible to contextualise school outcomes.

While much research attention has focused on the multiplicity of factors affecting school outcomes and on ways of reflecting them in assessing school performance, comparatively little has been said about how a school might improve its performance if it is found to be less effective than it might be. Yet identifying information that will help guide schools to improved performance is potentially more important in the long term than mere measures of their performance. Such measures, even contextualised ones, simply reflect past achievements. What a school and those who manage it need is guidance as to how the school might improve its performance. The approach outlined in this paper explains how DEA can be used to offer schools such guidance.

DEA offers distinct advantages over regression analysis as a source of information that will guide schools to improved performance. DEA is a "boundary" method so it estimates targets with reference to best performance for given values of the contextual variables. Regression analysis estimates targets with reference to average rather than best performance possible. DEA allows for subjective preferences over multiple educational outcomes to be reflected in setting targets. This would be problematic in regression analysis in the presence of multiple contextual and outcome variables. Finally DEA makes it possible to identify role-model schools most appropriate for each 
school. This is not possible in regression analysis. (For a more general comparison of DEA and regression analysis on target setting and other aspects see Thanassoulis8. Other uses of DEA to assess schools and LEAs can be found in Norman and Stoker9 (Sections 8.4 and 8.5), Smith and Mayston10 and Ganley and Cubbin11.)

The paper draws from an assessment of the schools of a local education authority (LEA) carried out by the authors. Data from that assessment are used to illustrate the approach developed in the paper. Secondary education schools in the case of this authority accept pupils from the age of 11. In all cases pupils stay at school to the age of 16 but some of the schools have "sixth forms" which cater for children aged 16 to 18 . The assessment from which the paper draws focussed on outcomes at the age of 16 and so data from all schools of the LEA was used.

The paper is structured as follows. The next section outlines the multiple outcomes and related contextual variables of the education process. The section is succeeded by one exploring whether constant or variable returns to scale characterise the education process. The last two sections explain how DEA can provide information useful in guiding a school to improved performance under uniform and variable preferences over educational outcomes respectively.

\section{CONTEXTUALISING THE PERFORMANCE OF SCHOOLS USING DEA}

DEA assesses performance by measuring the key inputs to and outputs from the process being monitored. In the case of schools the process monitored is the educational one. Hence for its assessment by DEA it is necessary to identify appropriate input and output variables. Figure 1 shows schematically how we see the school in the framework of a DEA assessment.

\section{FIGURE 1 - About here please}


The measured inputs and outputs refer to an individual cohort of pupils. The outputs reflect the final achievements of the cohort while the inputs (relating to that same cohort of pupils on transfer from primary school) reflect the environmental and other aspects affecting those achievements. What we are seeking is a measure of the school's ability to maximise the achievements of each cohort given the input levels that characterise the cohort.

The selection of variables should flow largely from work identifying factors influencing examination performance but it will also inevitably reflect the data available on the schools to be assessed. For the purposes of our illustrations it was desirable to choose input and output variables that describe as fully as possible the education process while also restricting their number. With the number of schools in the analysis being limited too many input and output variables could have resulted in loss of discrimination between schools. (See Dyson et al1.)

The input and output variables selected were as follows:

\section{Table 1 about here please}

The choice of the input and output variables is now briefly explained.

Verbal reasoning score

This variable is intended as a measure of the potential for academic attainment at school. Gray4 reviews a variety of studies linking examination performance to prior attainments and socioeconomic backgrounds and concludes that the best predictions of examination results are provided by verbal reasoning scores of pupils on intake, "social disadvantage" and percentage of pupils whose parents are from non-manual occupations. Attainment in Mathematics or English on entry could also have been used as measures of the potential for attainment of pupils at General Certificate of 
Secondary Education (GCSE) level. However, the three attainments were highly correlated and in the interests of parsimony verbal reasoning was deemed sufficient. (Readers unfamiliar with the British secondary education system may like to note that the GCSE is the qualification open to pupils at the end of their secondary education, normally at age 16. The certificate gives the grade achieved by the pupil on each subject on which they were assessed.)

\section{(ii) Percentage of pupils not receiving free school meals}

As noted above, Gray 4 posits that examination performance is also biased by the parental background of pupils. This is not dissimilar from the study by Charnes and Cooper12 which suggests that the level of parental education influences the results of children.

A number of alternative measures of parental background have been attempted. (See for example Jesson and Gray5.) The percentage not receiving free school meals selected here is used to reflect social advantage. This measure has been found to be highly associated with the achievement of pupils. (Jesson and Gray5). The measure is unsatisfactory to the extent that it does not discriminate within either those receiving or those not receiving free school meals but it is generally one of the most readily available measures believed to reflect social advantage.

(iii) Mean GCSE score per pupil

This measure is intended to reflect the academic attainment of a cohort. Few would dispute that academic attainment should be reflected as an outcome from the schooling process. However, there is less agreement as to how that attainment should be reflected.

Mean score per pupil has been computed by weighting examination grades as follows: 
Thus, for each cohort the number of A grades was multiplied by 8, the number of B grades by 7 and so on. These products were summed and then divided by the number of pupils in the cohort to compute the mean GCSE score per pupil.

One disadvantage of this measure is that subjective weights are being used for GCSE scores. The weights reflect an implicit "rate of exchange" between grades. For example a grade A is worth 8 grade Us. Our weighting system follows closely that used by Jesson and Gray5 . The difference is that we assign a weight of 1 to an unclassified GCSE grade. Jesson and Gray used the same weight of 0 for unclassified grades as well as for pupils that were absent from their examinations. It is arguable that a pupil gaining an unclassified grade shows more commitment than one that does not appear for the examination at all.

It was felt that it is important that the average GCSE grade should be computed per pupil rather than per pupil entered for examinations. In the contrary case a school could boost its mean GCSE grade by practicing selective entry of pupils for examinations.

The use of subjective weights for GCSE grades is naturally a weakness in the measure used. Strictly speaking the use of such weights is not necessary in a DEA assessment. The number of A grades, B grades and so on can be used as separate output variables. The model would then choose the weight it would assign to each grade in order to show a school at its most effective (maximum efficiency) relative to the remaining schools. If this approach had been adopted it would have been necessary to impose weights restrictions on the DEA model used so that better grades are given greater weight. The restriction would fall short of specifying the precise relative values of the weights attaching to each GCSE grade. (Models where preferences are used to restrict the values of DEA weights have been developed by several authors, notably Thompson et al13-14, Charnes et al15 and Dyson and Thanassoulis16.) 
We did not specify a separate output variable for each GCSE grade because the number of schools to be assessed was very small. The large number of output variables would have led to substantial loss of discriminatory power of the model used.

\section{(iv) Percentage of pupils not unemployed after GCSEs}

This output is used to reflect the achievement of schools in finding placements for their pupils upon completion of their studies. While we would expect that academic achievement and placement will be highly correlated in view of the fact that placement includes progression of pupils to further studies, it was nevertheless felt that securing placements for pupils is a separate outcome from teaching pupils. The outcome reflects a school's provision of career counselling and generally developing the social skills and attitudes necessary for progression to employment or further education. Should the pupils from schools face differing employment prospects due to the general economic condition in their area then that needs to be reflected in the model. This was not felt to be the case in this study in view of the fact that the schools were within the same geographical economic area.

\section{Funding per pupil}

It is noteworthy that what might appear at first sight as a very relevant input $\infty$ funding per pupil $\infty$ is excluded from the analysis. This is because of the use of "formula funding" for locally managed schools in the UK.

This funding system provides a constant amount per pupil in each year group throughout the LEA to cover direct teaching costs such as books or teachers' salaries. Additional funds are provided, based on estimates of the requirements of each school to cover overheads, such as heating or local taxes, or 
exceptional costs, such as the cost of running a special needs unit. It is argued that these extra costs are unlikely to advantage one school more than another in terms of its ability to transform the inputs into the outputs reflected in our model. Hence if the funding system is working appropriately, the funds per pupil available to each school for transforming inputs into educational outcomes is roughly constant and so unnecessary as an additional input in our model.

Many would dispute that the system of formula funding being used reflects accurately the relative needs of schools. Some schools may be advantaged while others disadvantaged by the system. Any systematic bias in the formula funding system may well show after a DEA assessment in the form of higher efficiencies for schools enjoying a higher level of overhead funding. In such a case a variable reflecting the total funding per pupil at each school will need to be incorporated in the assessment model.

\section{RETURNS TO SCALE IN THE EDUCATION PROCESS}

In a production process constant returns to scale hold if when the input levels of an efficient production unit are multiplied by a given factor its output levels are also multiplied by the same factor. Constant returns to scale cannot be assumed in situations where scale of operation has an impact on output levels so that there are "economies" or "diseconomies" of scale. The DEA models originally developed by Charnes et al17 assess the relative efficiencies of units assuming they operate under constant returns to scale. Banker et al18 developed DEA models for assessing the relative efficiencies of units operating under variable returns to scale. These models were later updated in Banker and Thrall19 to cover certain omissions in the earlier models.

The issue of the nature of returns to scale holding in the education process is important if a fair assessment of performance is to be made. However, little has been said hitherto about it in the context of the assessment of the effectiveness of the education process. 
In using input and output levels per pupil as defined in Table 1 we assume implicitly that constant returns to scale hold so far as size in terms of numbers of pupils is concerned. The plausibility of this assumption can perhaps be seen more clearly if the input and output variables are not normalised for the number of pupils at each school. The unnormalised input and output variables are as in Table 3.

\section{(Table 3 about here please)}

Teachers are the key agents for improving the achievements of pupils and the funding system provides for the same number of pupils per teacher across all schools. Thus there is no reason to expect that school size in itself will influence the ability of a school to get its pupils to improve their academic and employability achievements. So for example we could argue that if school A has twice the number of pupils of school B, and pupils are of similar ability and home background, then if the two schools are efficient school A should offer twice the total GSCE score and number of placements of school B. This argument supports the assumption of constant returns to scale in the education process so far as scale in terms of numbers of pupils is concerned.

However, the assumption of constant returns to scale is not as easily sustainable when "scale" relates to the values of the variables after they are normalised as in Table 1. For one thing all variables have upper limits $\infty$ for example no more than $100 \%$ of pupils can be placed. Even below the upper limits, we have no reason to expect that of two schools which operate efficiently and have the same number of pupils if one has say twice the input levels of the other it will also offer twice the output levels.

This difficulty is not peculiar to our input and output set alone. It will generally be encountered in assessing schools because educational achievements are usually measured on ordinal scales in the

form of A, B, C grades etc and there is no reason to expect achievements reflected on such scales 
will be simple multiples of the levels of the contextual variables (inputs) even if the mix of input levels is held constant.

At first sight a variable returns to scale assumption would appear more appropriate for the education process modelled using the input and output variables in Table 1. However, upon closer reflection this is found not to be a totally appropriate assumption either. Using mean values as in Table 1 poses a problem if the variable returns to scale assumption is adopted. The same mean value $\infty$ say on verbal reasoning $\infty$ could result from widely differing scores at individual pupil level at two schools. Such schools should not be comparable under the variable returns to scale assumption yet the model used will find them comparable because it will construe equal means on input levels as conveying the same "scale of operation". On the other hand schools with different mean input levels could have broadly similar distributions of scores at individual pupil level and may therefore be comparable. A variable returns to scale model would deem them not comparable.

Clearly neither the constant nor the variable returns to scale assumption is totally satisfactory for the assessment of schools. One way to alleviate the problem, adopted in our illustrative application, was to adjust the data to make it more compatible with a constant returns to scale assumption. The advantage of the constant returns to scale assumption is that all schools are deemed comparable, in principle, so that the method retains its discriminatory power. This is important when the schools to be assessed are few in number as was the case in our illustrative application. In order, however, to account for the fact that raw data on our input and output variables do not exhibit constant returns to scale it was decided to adjust the data so that it becomes more compatible with the constant returns to scale assumption. The adjustments were as follows.

The maximum raw verbal reasoning score per pupil was about 110 while the GCSE score per pupil, using the weights in Table 2, ranged up to 47. A regression was run of mean verbal reasoning score on mean GCSE score. It yielded an intercept of 75 on the verbal reasoning axis. (The regression was significant at the $1 \%$ level, $\mathrm{R} 2=87 \%)$. We took the intercept of the verbal reasoning score as 
indicating that only mean verbal reasoning scores above 75 are associated with improvements to mean GCSE scores. While clearly the causal relationship between verbal reasoning scores and GCSE grades is likely to be much more complex than is implied here, 75 was deemed a reasonable origin for mean verbal reasoning if mean verbal reasoning scores are to be linked in a proportional manner to mean GSCE scores. Hence 75 was deducted from mean verbal reasoning scores. This changed the ratio of the highest to the lowest verbal reasoning score in our set of schools from about 1.3 to 3.5. The corresponding ratio in the case of mean GCSE scores was about 2.5. The verbal reasoning and GCSE ratios are closer after adjusting verbal reasoning scores. This makes the adjusted data more compatible with constant returns to scale in that the assumption is plausible at least for efficient schools operating at either end of the verbal reasoning range.

Using a similar argument the percentages of pupils finding a place were adjusted. This time placements were regressed on the percentage not receiving free school meals. The intercept was 65 . (The regression was significant at the $1 \%$ level, $\mathrm{R} 2=76 \%$. ) Thus percentages of pupils finding a place were adjusted by subtracting 65 from each one.

Data on the input and output variables was available for 14 schools in our local education authority. The data was available over a 3 year period only. This was a serious drawback. The achievements of a cohort could not be related to its input levels on entry to the school since the time span between entry and exit from the school was 5 years. Under these circumstances we used input data relating to cohorts entering the schools at the same time as the cohorts whose outputs were being measured were leaving. Each school thus yielded 3 observations of input and output levels; one for each one of the years 1988/89, 1989/90, and 1990/91. So a total of $42 \infty 14 \times 3 \infty$ "schools" have been used in the illustrative assessments.

While the percentages of pupils not receiving free school meals are relatively stable over time the mean verbal reasoning scores are more variable. Therefore our results merely indicate the likely performance of each school rather than giving a true reflection of it. The usefulness of the analysis 
lies in its application in the future when input levels for each cohort could be related to its own output levels.

It must be noted that treating a school as a separate unit in each academic year made it necessary to adjust placements figures to reflect the continuing increase in unemployment in the UK between 1989 and 1991. The mean rate of pupils unemployed across our 14 schools in 1989 was $4.03 \%$. This rose to $5.74 \%$ in 1990 and 6\% in 1991. In order for fair year on year comparison to be made the 1990 and 1991 figures were scaled down such that the average rate of unemployment for each year was the same.

The data, adjusted for constant returns to scale and then scaled in the case of some of the variables, appear in Appendix 1. The scaling does not affect the DEA results and is merely used to enhance the confidentiality of the schools involved. Their names have been withheld. Each school is identified instead by a number. The first two digits identify the year to which the data relates and the remaining $\operatorname{digit}(\mathrm{s})$ the school.

\section{GUIDING SCHOOLS TO IMPROVED PERFORMANCE USING THE BASIC DEA MODEL}

Under the constant returns to scale assumption, the appropriate DEA model for assessing the performance of schools is the model developed by Charnes et al17. This is reproduced below as model (M1) set up to assess the performance of school jo. 
MIN Z $=V_{\text {vr }} V_{\text {Rj0 }}+V_{f s m}$ FSMj0

S.t.

$\mathrm{U}_{\mathrm{p}} \mathrm{Pj}_{\mathrm{j}}+\mathrm{Ug}_{\mathrm{g} 0}=100$

$U_{p} P_{j}+U_{g} G_{j}-V_{v r} V_{j}-V_{f s m} F_{S M j} \bullet 0 j=1 . . . j 0 \ldots 42$

$\mathrm{U}_{\mathrm{p}}, \mathrm{Ug}_{\mathrm{g}}, \mathrm{V}_{\mathrm{vr}}, \mathrm{V}_{\mathrm{fsm}} \geq 0.001$.

Notation in the model is as follows:

VR = Mean verbal reasoning score per pupil

FSM = Percentage not taking free school meals

G $\quad=$ Mean GCSE score per pupil

$\mathrm{P} \quad=$ Percentage of pupils placed upon leaving school.

The subscript $\mathrm{j}$ identifies the school. $\mathrm{V}_{\mathrm{vr}}, \mathrm{V}_{\mathrm{fsm}}, \mathrm{Ug}_{\mathrm{g}}$ and $\mathrm{U}_{\mathrm{p}}$ are weights attaching to VR, FSM, G and $\mathrm{P}$ respectively and they are the variables in this model. The relative efficiency of school j0 is Ej0 $=100 / Z^{*}, Z^{*}$ being the optimal value of $Z$ in (M1). (For the derivation of (M1) see Charnes et al17). Ej0 is the proportion school jo achieves of the maximum output levels it could have achieved if it operated efficiently. School jo is relatively efficient if $\mathbf{E} \mathbf{j 0}=\mathbf{1}$.

Model (M1) is one of the "basic" DEA models. Extended DEA models have been developed to cater for assessments of efficiency in situations involving factors which cannot be handled in basic DEA models. (For a review of basic and extended DEA models see Charnes et al20.) This section illustrates how information yielded by a DEA assessment using the basic DEA model in (M1) can be used for guiding schools to improved performance. The next section will use an extended DEA model suitable for guiding schools to improved performance. 
Model (M1) applied to each school in turn reveals whether it is relatively efficient or not. Our aim is to guide relatively inefficient schools to improved performance. Most useful for this aim is the identification of

- $\quad$ "efficient peers" for each inefficient school and
- $\quad$ target levels which would render a school relatively efficient.

\section{Efficient peers}

The efficient peers of school jo are the schools which have efficiency of 1 (or $100 \%)$ when the weights optimal for school jo are applied to their own input and output levels.

Efficient peer schools for school jo are readily identified by the fact that if the jth school is an efficient peer to school jo then at the optimal solution to (M1) the constraint

$\mathrm{U}_{\mathrm{p}} \mathrm{P}_{\mathrm{j}}+\mathrm{Ug}_{\mathrm{g}} \mathrm{G}_{\mathrm{j}}-\mathrm{V}_{\mathrm{Vr}} \mathrm{VR}_{\mathrm{j}}-\mathrm{V}_{\mathrm{fsm}} \mathrm{FSM}_{\mathrm{j}} \bullet 0$

is binding.

School jo chooses values for the input and output weights which show it in the best possible light. These weights render its peers relatively efficient. This makes the peers useful because they have better performance at precisely the areas school jo chooses to emphasise (weight heavily) when compared to other schools. As a result it is likely there is a measure of agreement (explicit or implicit) between school j0 and its efficient peers on the relative values of the educational outcomes and the relative strength of the environmental influences on those outcomes. Thus the efficient peers can act as role-models for school jo in its effort to improve its performance. 
An example will help illustrate the point. In assessing the schools of our illustrative LEA School SC9010 was found to have relative efficiency of 72.74\%. The relative efficiency of school SC9010 means that relative to its efficient peers, the output levels of school SC9010 are only at $72.74 \%$ of their potential levels. The efficient peer schools for school SC9010 were SC912 and SC913. We can now contrast the performance of SC9010 with that of its efficient peers to see how its performance is poorer.

\section{Table 4 about here please}

The table shows the actual data for SC912 and SC913 and also the same data scaled by the factor labelled SCALE. The scaling makes comparison between the inefficient school and its efficient peers easier. Both peers have been scaled so that none of their input levels exceeds the corresponding input level of school SC9010 and one input level of the peer equals the corresponding level of school SC9010. Comparison of the scaled peers with school SC9010 can now be on outputs only. (The assessment was carried out using the Warwick DEA Software (Halstead et al21) where the user can control the scaling process for making comparisons between peers and the inefficient unit easier.) For convenient identification input variables have the prefix "-" and output variables the prefix "+" throughout this paper.

It is relatively easy to see that the efficient peers perform better than school SC9010 when the scaled data are compared. It is recalled that the data has already been adjusted to be compatible with a constant returns to scale assumption and so scaling in this way for comparative purposes is acceptable. School SC912 in its scaled form has no higher input levels than school SC9010 but its output levels are much higher than those of school SC9010. A similar statement can be made in respect of inputs for school SC913 though the record on placements is this time slightly better at SC9010. 
Contrasting inefficient schools with their peers in this way can help reinforce the case that the inefficient school needs to improve performance. Once the peers are identified the arguments for improving performance at the inefficient school can be made using straightforward comparisons of input and output levels as in Table 4. The comparisons need not refer back to the DEA concepts and so they are suitable for the lay-person.

Some of the efficient peers are normally better role-models for the inefficient unit that its other peers. This is best seen using the actual data of the efficient peers shown in Table 4. (Note that throughout this paper the data labelled "actual" is after the adjustments for constant returns to scale and scaling noted earlier.)

In the case of school SC9010 pupils offer mean verbal reasoning score of 45 while those entering its peer school SC913 offer a mean verbal reasoning score of 94.5. Therefore school SC913 is unlikely to prove a useful role-model for school SC9010 because the two schools have intakes of substantially differing ability.

However, the second peer, school SC912, may well prove a useful role-model for school SC9010. Pupils of school SC912 offer a mean verbal reasoning score of 47.4 upon entry to the school and this is not substantially different from the mean verbal reasoning score offered by pupils entering school SC9010. Some $81 \%$ of pupils of school SC912 do not receive free school meals compared to $67 \%$ in the case of school SC9010. This suggests the intake to school SC912 may enjoy greater levels of home support that pupils of school SC9010 do. Even allowing for this apparent advantage pupils at school SC912 enjoy, (see scaled levels of school SC912) their performance is better than that of pupils at school SC9010. The superior performance of school SC912 is perhaps more convincing at the unscaled level. The mean GCSE score at school SC912 is 62.26 compared to 40.5 at school SC9010 and placements at school SC912 are 96.35\% (31.35 + 65) compared to $82.34 \%$ at school SC9010. Such differences are unlikely to be explained by differences in home support alone that 
pupils enjoy at the two schools. The two schools teach pupils of approximately the same ability and so school SC9010 may benefit from exploring the practices of school SC912.

An inefficient school can, of course, study and adopt operating practices from any efficient school whether or not it is one of its efficient peers. What makes its efficient peers special is that they are efficient with the very value system that would show the inefficient school in the best light. Hence they are likely to offer operating practices and environments compatible with those of the inefficient school. This would make them suitable as role-models the inefficient school can emulate to improve its performance.

\section{Setting targets for inefficient schools}

Input-output levels which would render school jo efficient can be deduced directly from the optimal solution to model (M1). They are more conveniently explained with reference to the optimal solution to the dual to model (M1). This is reproduced as model (M2) below.

$$
\operatorname{Max} \mathrm{Z}=\Theta+0.001(\mathrm{SVR}+\mathrm{SFSM}+\mathrm{SG}+\mathrm{SP})
$$

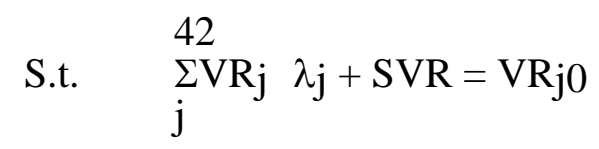

42

$\sum_{j} F M_{j} \lambda_{j}+S F S M=F S M j 0$

$\Theta \mathrm{Gj}_{0}-\quad \sum_{\mathrm{j}}^{42} \mathrm{Gj} \lambda_{\mathrm{j}}+\mathrm{SG}=0$

$\Theta P_{j 0}-\quad \sum_{j}^{42} P_{j} \lambda_{j}+S P=0$

$\lambda_{\mathrm{j}} \mathrm{j}=1 \ldots 42, \mathrm{SVR}, \mathrm{SFSM}, \mathrm{SG}$ and $\mathrm{SP} \geq 0, \Theta$ free.

In (M2), $\Theta, \lambda_{j}, \mathrm{SVR}, \mathrm{SFSM}, \mathrm{SG}$ and SP are the variables in the model. Notation is otherwise as in (M1). (The optimal solution of (M2) can, of course, be deduced from that of (M1) or vice versa and 
so only one of the models need be solved to assess school j0.) Model (M2) identifies "feasible" output levels which offer the maximum pro-rata increase $\infty$ represented by the optimal value of the factor $\Theta \infty$ to the current output levels of school jo given its input levels. The optimal values of SVR, SFSM, SG and SP identify any further input reductions or output increases which might have been feasible after the pro-rata rises in the output levels. These input and output levels are VR', FSM', G' and P' for mean verbal reasoning score, percentage not on free school meals, mean GCSE score and placements respectively, where

$$
\begin{aligned}
& V^{\prime}=\sum_{j}^{42} V^{\prime} \lambda_{j}{ }^{*} \\
& \text { FSM' }^{\prime}=\sum_{\mathrm{j}}^{42} \mathrm{FSM}_{\mathrm{j}} \lambda_{\mathrm{j}}{ }^{*} \\
& G^{\prime} \quad=\sum_{j}^{42} G_{j} \lambda_{j}{ }^{*} \\
& P^{\prime} \quad=\quad \sum_{j}^{42} P_{j} \lambda j^{*}
\end{aligned}
$$

The superscript * denotes the optimal value of $\lambda_{\mathrm{j}}$ in (M2). The levels (VR', FSM', G', P') would render school jo relatively efficient and they can be used as targets for it. For the derivation of (M2) and the targets in (1) see Charnes et al17.

Table 5 below illustrates the targets yielded by (M2) for school SC9010.

\section{(Table 5 about here please)}

The targets indicate that for the mean verbal reasoning score of its pupils and given that about $67 \%$ of them do not receive free school meals, School SC9010 ought to offer a mean GCSE score of 55.67 
and place some $25.35(+65)$ or nearly $90 \%$ of its pupils on leaving school. The targets reflect what ought to be feasible so far as school SC9010 is concerned if the assumptions underlying model (M2) (notably the assumption of constant returns to scale) hold. In practice the targets in (1) are likely to be useful only as a starting point. They may well need subjective adjustments to reflect factors not incorporated in model (M2).

Targets such as those in Table 5 do not reflect any emphasis on improving specific educational outcomes at a school. They merely indicate the maximum pro-rata improvement feasible to all outcomes at a school. However, it is often desirable to have variable degrees of improvement across educational outcomes at a school. For example it may prove desirable to improve English results by a bigger proportion than mathematics results at a school. It is necessary to use extended DEA models to estimate such targets and identify related efficient peers. The next section illustrates how this can be done.

\section{GUIDING SCHOOLS TO IMPROVED PERFORMANCE USING EXTENDED DEA MODELS}

The two educational outcomes reflected in our input and output variables in Table 1 are GCSE scores and placements of pupils. It is entirely possible that a school may wish to attain efficiency by not giving equal priority to improving its performance on both variables. For example it may feel that its targets should reflect a higher priority for improving its mean GCSE score than for raising the percentage of pupils placed on leaving school. This section illustrates the appropriate DEA models to use to estimate targets where priorities over the improvement of output levels are not uniform. 


\section{Prioritised targets}

Thanassoulis and Dyson22 have developed DEA models which can be used to set performance targets for an inefficient unit which reflect varying preferences over improvements to given input or output levels. These models can be used to set performance targets for schools compatible with expressed preferences over the relative desirability of improving the levels of individual outputs. (The models are similar to those in Thompson et al13-14, Charnes et al15 and Dyson and Thanassoulis16 in that they enhance the DEA model solved by making use of decision-maker preferences.)

The approach is illustrated for the case where it is desired to estimate targets in which the improvement of the mean GCSE score is to be given pre-emptive priority. The following extended DEA model (originally developed in Thanassoulis and Dyson22) can be used to estimate targets:

Max H + 0.001( SVR + SFSM + SP)

S.t

42

$\sum_{j} V_{R j} \lambda_{j}+S V R=V R j 0$

42

$\sum_{\mathrm{j}} \mathrm{FSM}_{\mathrm{j}} \lambda_{\mathrm{j}}+\mathrm{SFSM}=\mathrm{FSM} \mathrm{j} 0$

$\mathrm{HG}_{\mathrm{j} 0}-\quad \sum_{\mathrm{j}}^{42} \mathrm{G}_{\mathrm{j}} \lambda_{\mathrm{j}}=0$

42

$\sum_{j} P_{j} \lambda_{j}-S P=P_{j} 0$

$\lambda_{\mathrm{j}} \mathrm{j}=1 \ldots 42, \mathrm{SFSM}, \mathrm{SVR}$ and $\mathrm{SP} \geq 0, \mathrm{H}$ free. 
Notation in (M3) is as in (M2). The subscript jo identifies the school for which targets are sought.

Model (M3) differs from (M2) in that the factor being maximised, $\mathrm{H}$, multiplies only the level of $\mathrm{G}$ at school j0. This level is being given priority to improve within the targets to be estimated. In (M2) the factor $\Theta$, corresponding to $\mathrm{H}$ in (M3), multiplies all output levels. The structure of (M3) ensures that it identifies target input and output levels which offer the maximum increase to the mean GCSE score of school jo given its input levels and without detriment to the percentage of its pupils found places on leaving school. (For the full derivation of the generic model on which (M3) is based see

Thanassoulis and Dyson22 (model (M2).) The targets yielded by model (M3) in respect of school j0 are given by the RHSs of the equations in (1) using the optimal $\lambda$ values from (M3).

Models (M2) and (M3) generally, though not necessarily always, yield different targets in respect of school jo. The targets yielded by model (M2) depend on the extent to which the pro-rata increase to all output levels is possible. In contrast, (M3) yields targets which exploit the maximum increase possible to the level of the output selected $\infty$ mean GCSE score. Table 6 illustrates the difference in the targets yielded by the two models in respect of school SC8914.

\section{Table 6 about here please}

If school SC8914 wishes to give equal emphasis to the improvement of its two output levels then it should aim to raise by some $24 \%$ its current (adjusted) output levels to attain relative efficiency. In contrast, if the school wishes to give priority to the improvement of its academic results over placements then it should raise its mean GCSE score by some $42 \%$ and its (adjusted) placements by some $17 \%$ in order to become relatively efficient. Thus, the targets yielded by model (M3) offer a trade off so that a larger improvement in academic results is expected at the expense of a lower proportion of pupils placed on leaving school. 
A further point is worthy of note in Table 6. Although models (M2) and (M3) seek targets which maximise output levels they have as second order priority an incentive to identify whether the target output levels are feasible, in principle, even with lower input levels than the school enjoys at present. (This is achieved through seeking positive values for SFSM and SVR in (M2) and (M3).) It can be seen in Table 6 that the solution of the models reveals that when pre-emptive priority is given to maximising mean GCSE score school SC8914 cannot afford to admit pupils of lower mean verbal reasoning score than 50.1 offered by its current intake if it is to achieve its targets. In contrast, when equal priority is given to raising academic results and placements, the school can, in principle, achieve its targets even if pupils admitted offered the slightly lower mean verbal reasoning score of 48.6 rather than the current 50.1.

\section{Efficient peers compatible with prioritised targets}

Particularly valuable is the fact that model (M3) yields efficient peers which would prove most appropriate role-models for a school given its preferences over improvements to its outputs. Table 7 shows the efficient peers for school SC8914 depending on whether it desires equal or special priority targets.

\section{Table 7 about here please}

The peers are scaled in a manner similar to that in Table 4. It is quite clear that the peers identified when the maximisation of the mean GCSE score is given priority over placements $\infty$ schools SC912 and SC913 $\infty$ offer better academic achievements than the peers $\infty$ schools SC8912 and SC9111 $\infty$ identified when the two outputs are given equal priority to improve.

To see this note that peers in Table 7 are scaled so that none has input levels larger than those of school SC8914. Thus they can all be compared directly with school SC8914 focusing on output 
levels only. All peers offer a better mean GCSE score than school SC8914. However, schools SC912 and SC913 offer much better academic results than peer schools SC8912 and SC9111. This makes schools SC912 and SC913 suitable for school SC8914 to emulate when it wishes to improve its mean GCSE score above all else.

\section{Generalising preferences over improving educational outcomes}

The models developed in Thanassoulis and Dyson22 permit the use of a general preference structure over improvements to outcomes. The preference structure used in model (M3) is merely a special case of the more general situation where improvements are desired to all outcomes but to varying degrees. The model that can be used to estimate targets and appropriate peers for school j0 in this case is as follows:

Max W1 H1 + W2 H2+ 0.001( SVR + SFSM )

S.t.

42

$\sum V_{\mathrm{j}} \lambda_{\mathrm{j}}+\mathrm{SVR}=\mathrm{VR}_{\mathrm{j} 0}$

$\mathrm{j}$

42

$\Sigma F S M j \lambda_{j}+S F S M=F S M j 0$

$\mathrm{j}$

$\mathrm{H} 1 \mathrm{Gj} 0-\quad \sum_{\mathrm{j}}^{42} \mathrm{G}_{\mathrm{j}} \lambda_{\mathrm{j}}=0$

$\mathrm{H} 2 \mathrm{Pj}_{\mathrm{j} 0}-\quad \sum_{\mathrm{j}}^{42} \mathrm{P}_{\mathrm{j}} \lambda_{\mathrm{j}}=0$

H1, H2 $\geq 1$,

$\lambda_{\mathrm{j}} \mathrm{j}=1 . . .42, \quad$ SFSM and SVR $\geq 0$. 
W1 and W2 are user-specified weights, reflecting the relative degree to which improvement to the mean GCSE score and placements respectively is desired. The lower bounds on H1 and H2 ensure that the targets yielded by (M4) will involve no deterioration to the current output levels of school j0. Notation in (M4) is otherwise the same as in (M3). The targets yielded by model (M4) in respect of school j0 are given by the RHSs of the equations in (1) using the optimal $\lambda$ values from (M4). The model identifies not only targets but also peer schools for school jo compatible with its preferences over improvements to output levels. (For the generic model on which (M4) is based see Thanassoulis and Dyson22 (model (M3)).

The targets and peer schools yielded by model (M4) in the case of school SC8914 as alternative preferences are incorporated over improvements to its two output levels are illustrated in Table 8.

\section{Table 8 about here please}

Clearly as the weight attached to improving GCSE scores is reduced, the corresponding target level is lowered to the benefit of placements. It is interesting that in the final column, where the weight to improving GCSE scores is at its lowest, the targets suggest that a good academic ability of pupils on intake, as reflected by their mean verbal reasoning score, is no longer essential. The current mean verbal reasoning score of 50.1 can drop to 40.1 as the emphasis switches from a desire to improve the mean GCSE score to improving placements.

The efficient peers identified for school SC8914 vary depending on its preferences over improving individual educational outcomes. The peers range from those suitable when equal priority is given to improving the two outputs to those suitable when the improvement of academic results is given preemptive priority. Table 9 shows the mean GCSE score of each peer school when its input and output levels are scaled as in Table $7 \infty$ ie. so that no peer input level exceeds the corresponding level at school SC8914. 


\section{Table 9 about here please}

As the weight given to improving the mean GCSE score decreases so does the mean GCSE score of the efficient peers selected.

\section{CONCLUSION}

This paper has shown how DEA can be used to extract information from the observed performance of schools which will help those deemed relatively inefficient to improve their performance.

It is generally accepted that the educational process has multiple outcomes which include not only academic but also non-academic achievements. The efficiency of a school in adding value to the outcomes achieved by its pupils needs to be assessed after allowing for the context in which the school operates including the academic ability of its pupils on entry to the school and the parental or other support they enjoy.

The paper put forward input and output variables which can be used to assess the comparative efficiencies of schools in improving the educational outcomes of their pupils while allowing for the environment in which each school operates. It was argued that neither constant nor variable returns to scale can describe adequately the production process in which schools are engaged if raw academic and other results are used for the input and output variables selected. Adjustments to the data were made so that it becomes more compatible with a constant returns to scale assumption.

The paper showed first how targets can be estimated which would render a school relatively efficient. These targets were based on an equal desire to improve all the outcomes of the education process. The DEA model suitable for this aim was the "basic" DEA model developed by Charnes et 
al17. The model also identifies suitable role-model schools which an inefficient school can emulate to improve its performance and move towards achieving its targets.

Finally the paper showed the use of extended DEA models (developed by Thanassoulis and Dyson22) which make it possible to estimate targets which would render a school relatively efficient while reflecting varying preferences over improvements to individual educational outcomes. The models also identify peer schools an inefficient school can emulate to improve its performance in line with its preferences over educational outcomes. 


\section{APPENDIX 1}

\section{Data Used in the Assessment - (adjusted and scaled values)}

\begin{tabular}{|c|c|c|c|c|}
\hline \multirow[t]{3}{*}{ School } & \multirow{2}{*}{$\begin{array}{l}\text { Mean Verbal } \\
\text { Reasoning }\end{array}$} & \multirow{2}{*}{$\begin{array}{l}\text { Percent } \\
\text { not on }\end{array}$} & \multirow{3}{*}{$\begin{array}{l}\text { Percent } \\
\text { Placed } \\
\text { (P) }\end{array}$} & \multirow{3}{*}{$\begin{array}{l}\text { Mean GCSE } \\
\text { Score (G) }\end{array}$} \\
\hline & & & & \\
\hline & $\begin{array}{l}\text { Score } \\
\text { (VR) }\end{array}$ & $\begin{array}{l}\text { Free School } \\
\text { Meals (FSM) }\end{array}$ & & \\
\hline SC891 & 80.1 & 97.43 & 34.58 & 85.25 \\
\hline SC892 & 47.4 & 82.48 & 30.35 & 54.56 \\
\hline SC893 & 101.4 & 100.00 & 34.55 & 92.51 \\
\hline SC894 & 97.5 & 97.89 & 34.57 & 79.81 \\
\hline SC895 & 79.2 & 96.59 & 33.39 & 70.07 \\
\hline SC896 & 81.9 & 97.12 & 32.22 & 76.53 \\
\hline SC897 & 88.2 & 95.15 & 31.46 & 74.72 \\
\hline SC898 & 72.9 & 96.10 & 31.20 & 65.24 \\
\hline SC899 & 61.5 & 90.84 & 29.60 & 65.95 \\
\hline SC8910 & 37.2 & 74.60 & 23.98 & 41.61 \\
\hline SC8911 & 33.0 & 75.49 & 26.79 & 38.58 \\
\hline SC8912 & 86.7 & 95.80 & 35.10 & 90.53 \\
\hline SC8913 & 91.8 & 99.56 & 33.80 & 98.73 \\
\hline SC8914 & 50.1 & 76.50 & 24.71 & 44.01 \\
\hline SC901 & 77.4 & 97.35 & 32.45 & 80.46 \\
\hline SC902 & 52.2 & 79.18 & 28.76 & 54.28 \\
\hline SC903 & 99.9 & 99.51 & 34.61 & 94.33 \\
\hline SC904 & 80.4 & 97.20 & 33.42 & 80.29 \\
\hline SC905 & 81.3 & 94.50 & 34.55 & 74.46 \\
\hline
\end{tabular}


Target Setting for Schools by DEA

\begin{tabular}{|c|c|c|c|c|}
\hline SC906 & 77.7 & 97.11 & 32.21 & 69.56 \\
\hline SC907 & 89.1 & 96.08 & 31.18 & 74.88 \\
\hline SC908 & 66.0 & 94.34 & 32.05 & 64.78 \\
\hline SC909 & 63.3 & 90.28 & 33.48 & 63.44 \\
\hline SC9010 & 45.0 & 67.29 & 17.34 & 40.50 \\
\hline SC9011 & 42.3 & 75.13 & 24.21 & 42.62 \\
\hline SC9012 & 95.1 & 96.15 & 34.45 & 89.96 \\
\hline SC9013 & 89.1 & 99.09 & 34.19 & 92.86 \\
\hline SC9014 & 54.3 & 72.34 & 24.46 & 44.95 \\
\hline SC911 & 83.1 & 96.85 & 31.95 & 81.16 \\
\hline SC912 & 47.4 & 81.28 & 31.35 & 62.26 \\
\hline SC913 & 94.5 & 99.44 & 34.54 & 102.36 \\
\hline SC914 & 85.2 & 97.43 & 34.45 & 83.37 \\
\hline SC915 & 84.6 & 96.34 & 32.66 & 83.40 \\
\hline SC916 & 75.9 & 96.74 & 32.77 & 86.87 \\
\hline SC917 & 91.2 & 94.88 & 30.55 & 81.17 \\
\hline SC918 & 74.1 & 94.97 & 31.74 & 65.86 \\
\hline SC919 & 62.1 & 90.12 & 29.52 & 64.77 \\
\hline SC9110 & 43.5 & 71.91 & 23.86 & 46.98 \\
\hline SC9111 & 39.9 & 74.45 & 30.75 & 46.68 \\
\hline SC9112 & 89.7 & 96.31 & 28.96 & 92.35 \\
\hline SC9113 & 94.8 & 99.07 & 34.17 & 100.36 \\
\hline SC9114 & 41.7 & 75.00 & 27.74 & 47.51 \\
\hline
\end{tabular}



Inputs

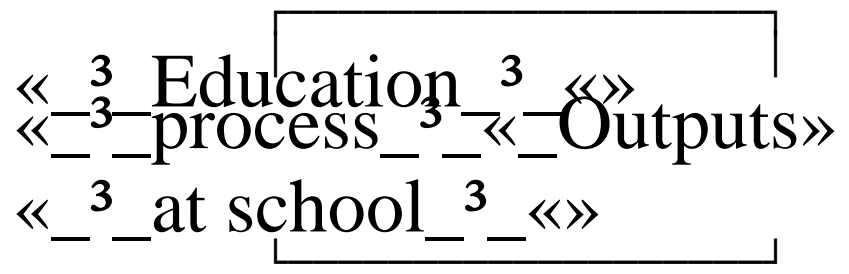

Figure 1: Schematic representation of a school in the context of assessment by DEA 


\section{Table 1}

\section{Inputs}

1 Mean verbal reasoning 1 score per pupil on entry

2 Percentage not receiving 2 free school meals

\section{Outputs}

1 Average GCSE score per pupil

Percentage of pupils not unemployed after GCSEs 


\section{Table 2}

Weights used to compute a single measure of academic achievement

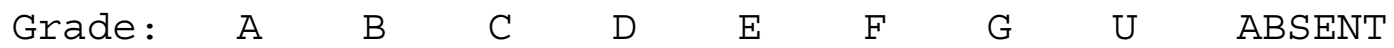

Weight: $\quad 8 \quad 7 \quad \begin{array}{llllllll} & 8 & 5 & 4 & 3 & 2 & 1 & 0\end{array}$


Table 3

Unnormalised Input-Output Variables

\section{Inputs}

1 Total verbal reasoning score on entry over all pupils

2 Number of pupils not receiving free school meals
Outputs

1 Total GCSE score over all pupils

$2 \quad$ Number of pupils not unemployed after GCSES 
Table 4

Efficient Peer Schools for SC9010 with efficiency $72.74 \%$

\begin{tabular}{|c|c|c|c|c|c|}
\hline \multirow{2}{*}{\multicolumn{2}{|c|}{$\begin{array}{l}\text { SC9010 } \\
\text { ACTUAL }\end{array}$}} & \multicolumn{2}{|c|}{ SC912 } & \multicolumn{2}{|c|}{ SC913 } \\
\hline & & ACTUAL & SCALE & ACTUAL & SCALE \\
\hline 67.29 & - FSM & 81.28 & 67.29 & 99.44 & 47.35 \\
\hline 45.0 & -VR & 47.4 & 39.2 & 94.5 & 45.0 \\
\hline 50 & $+\mathrm{G}$ & 62.26 & 51.54 & 102.36 & 48.74 \\
\hline 7.34 & $+\mathrm{P}$ & 31.35 & 25.95 & 34.54 & 16.45 \\
\hline
\end{tabular}


Table 5

Targets for school SC9010

Targets for Unit SC9010 VARIABLE

- FSM

$-V R$

$+\mathrm{G}$

$+\mathrm{P}$
ACTUAL

67.29

40.50

17.34
45.0 efficiency $72.74 \%$ radial

TARGET TO GAIN ACHIEVED

67.29

45.0

$0.0 \%$

$0.0 \%$

$100.0 \%$

$100.0 \%$

55.67

25.35

$37.5 \%$

$46.2 \%$

$72.7 \%$

$68.4 \%$ 
Table 6

Equal and Special Priority Targets for School SC8914

VARIABLE

- FSM

-VR

$+\mathrm{G}$

$+\mathrm{P}$
EQUAL

PRIORITY

TARGETS

ACTUAL

76.50

50.1

44.01

24.71
SPECIAL

PRIORITY

"MAX G"

TARGETS

76.50

48.6

76.50

50.1

54.55

30.63

62.48

28.93 
SC8914

ACTUAL

$$
\begin{array}{cl}
76.50 & - \text { FSM } \\
50.1 & - \text { VR }
\end{array}
$$$$
44.01+\mathrm{G}
$$

$24.71+\mathrm{P}$
Table 7

Efficient Peers for School SC8914

EQUAL PRIORITY TARGETS

SC8912 SC9111

1.028

$55.36 \quad 76.50$

$50.1 \quad 41.0$

44.61

$52.31 \quad 47.97$

$20.28 \quad 31.60$

$58.59 \quad 54.27$
$29.50 \quad 18.31$

(MAX G)

SC912 SC913

$\begin{array}{ll}0.941 & 0.53\end{array}$

$6.50 \quad 52.71$ 


\section{Table 8}

Targets for School Sc8914 under Varying Preferences over Outcome Improvements

\begin{tabular}{|c|c|c|c|}
\hline GCSE SCORE WEIGHT & 35 & 28 & 10 \\
\hline $\begin{array}{l}\text { ACTUAL } \\
\text { LEVELS }\end{array}$ & & & \\
\hline $\begin{array}{c}76.50 \text {-FSM } \\
50.1 \text {-VR }\end{array}$ & $\begin{array}{l}76.50 \\
50.1\end{array}$ & $\begin{array}{l}76.5 \\
50.1\end{array}$ & $\begin{array}{l}76.5 \\
40.1\end{array}$ \\
\hline $\begin{array}{l}44.01+G \\
24.71+P\end{array}$ & $\begin{array}{l}61.65 \\
29.18\end{array}$ & $\begin{array}{l}55.80 \\
30.44\end{array}$ & $\begin{array}{l}47.95 \\
31.59\end{array}$ \\
\hline
\end{tabular}


Table 9

Efficient Peers for School SC8914 under Varying Preferences over Outcome Improvements

Placements weight $=75$, Zero weights on inputs

GCSE SCORE WEIGHT =

35

28

10

EFFICIENT PEERS

SC912 SC8912

58.5952 .31

SC8912 SC9111

52.31

47.97

SC9111

G

47.97 


\section{References}

1 R. G. Dyson, E. Thanassoulis and A. Boussofiane, (1990), Data envelopment analysis, in Operational Research Tutorial Papers, L.C. Hendry and R. Eglese (editors), pp. 13-28, published by The Operational Research Society, UK.

2 Boussofiane, A., Dyson, R.G. and Thanassoulis, E. (1991), Applied Data Envelopment Analysis, European Journal of Operational Research, 15 (5), 1-15.

3 Hutchinson, D., Prosser, H. and Wedge, P. (1979) The prediction of educational failure, Educational Studies, 5, 1, pp 73-82.

4 Gray, J. (1981), A Competitive Edge : Examination Results and the probable limits of secondary school effectiveness. Educational Review, Volume 33, Number 1, pp 25-35

5 Jesson, D. and Gray, J. (1991) : Pupil performance in context, Qualitative and Quantitative Studies in Education Research Group, Division of Education, University of Sheffield, UK. (Published by the LEA, Nottinghamshire County Council, Nottingham, UK.)

6 Gray, J. Jesson, D. and Jones, B. (1986) The search for a fairer way of comparing schools examination results. Research papers in Education, Volume 1, number 2, pp 91-122.

7 Mayston D and Jesson, D. (1988), Developing models of educational accountability, Oxford Review of Education, Vol. 14, No. 3, 1988.

8 Thanassoulis, E. (1993), A comparison of regression analysis and data envelopment analysis as alternative methods for performance assessments. Journal of the Operational Research Society, Vol 44, No 11, pp. 1129-1144.. 
9 Norman, M., and Stoker, B. (1991), Data Envelopment Analysis the Assessment of Performance, John Wiley \& Sons, England.

10 Smith, P. and Mayston, D. J. (1987), Measuring efficiency in the public sector, OMEGA $\infty$ the International Journal of Management Science, 15, pp. 243-257.

11 Ganley, J. A. and Cubbin, J. S., (1992), Public Sector Efficiency Measurement, North Holland, London.

12 Charnes, A., Cooper, W. and Rhodes, E., (1981), Evaluating Program and Managerial Efficiency: An Application of Data Envelopment Analysis to Program Follow Through, Management Science, Vol. 27, No. 6, pp. 668-697.

13 Thompson R. G., Singleton Jr F. D., Thrall R. M. and Smith B. A, (1986), Comparative site evaluations for locating high energy Lab in Texas, TIMS Interfaces, 16, pp. 1380-1395.

14 Thompson R. G., Langemeier L. N., Lee C. T., Lee E., and Thrall R. M. (1990), The role of multiplier bounds in efficiency analysis with application to Kansas farming. Journal of Econometrics, 46, pp. 93-108.

15 Charnes A, Cooper W. W., Huang Z. M., and Sun B. (1990) Polyhedral cone-ratio DEA models with an illustrative application to large commercial Banks, Journal of Econometrics, 46, pp. 73-91.

16 R. G. Dyson and E. Thanassoulis (1988), Reducing weight flexibility in data envelopment analysis. J. Opl Res. Soc., Vol. 39, No. 6. pp. 563-576.

17 Charnes, A., Cooper, W. and Rhodes, E., (1978) Measuring the efficiency of decision making units, European Journal of Operational Research 2, 429-444. 
18 Banker, R. D. Charnes, A. and Cooper, W, (1984), Some models for estimating technical and scale inefficiencies in Data Envelopment Analysis, Management Science, 30, 1078-1092.

19 Banker R. D. and Thrall R. M. Estimation of returns to scale using data envelopment analysis, European Journal of Operational Research, 62, pp. 74-84.

20 Charnes A., Cooper W. W., Lewin Arie Y, Seiford Lawrence M., editors, (forthcoming). Data Envelopment Analysis: Theory, Methodology, and Applications: Kluwer Academic Publishers, Norwell, Ma, USA.

21 Halstead, K., Thanassoulis, E. and Dyson, R. G. (1989), Using the Warwick DEA Software, Warwick Business School, Warwick University, Coventry CV4 7AL, UK. (User Guide)

22 Thanassoulis, E. and Dyson, R. G. (1992) Estimating preferred input and output levels using data envelopment analysis. European Journal of Operational Research., Vol 56, pp. 80-97. 